\title{
A Randomized Controlled Study of Parent-assisted Children's Friendship Training with Children having Autism Spectrum Disorders
}

\author{
Fred Frankel · Robert Myatt • Catherine Sugar • \\ Cynthia Whitham • Clarissa M. Gorospe • \\ Elizabeth Laugeson
}

Published online: 8 January 2010

(c) The Author(s) 2010. This article is published with open access at Springerlink.com

\begin{abstract}
This study evaluated Children's Friendship Training (CFT), a manualized parent-assisted intervention to improve social skills among second to fifth grade children with autism spectrum disorders. Comparison was made with a delayed treatment control group (DTC). Targeted skills included conversational skills, peer entry skills, developing friendship networks, good sportsmanship, good host behavior during play dates, and handling teasing. At post-testing, the CFT group was superior to the DTC group on parent measures of social skill and play date behavior, and child measures of popularity and loneliness, At 3-month follow-up, parent measures showed significant improvement from baseline. Post-hoc analysis indicated more than $87 \%$ of children receiving CFT showed reliable change on at least one measure at post-test and $66.7 \%$ after 3 months follow-up.
\end{abstract}

keywords Social skills training - Autism ·

Asperger's disorder

\section{Introduction}

It has been a mixed blessing for children with Asperger's Disorder or High Functioning Autism (ASD) to be placed in regular education classrooms (Burack et al. 1997). On

F. Frankel $(\bowtie) \cdot$ R. Myatt - C. Sugar - C. Whitham .

C. M. Gorospe · E. Laugeson

UCLA Semel Institute For Neuroscience and Human Behavior, 300 UCLA Medical Plaza, Los Angeles, CA 90095, USA

e-mail: ffrankel@mednet.ucla.edu

C. Sugar

Department of Biostatistics, UCLA School of Public Health, Center For Health Sciences, Los Angeles, CA 90095-1772, USA the one hand, such placement has been associated with increases in the complexity of their play and decreases in nonsocial activity when compared to how they behave in special education settings (Sigman and Ruskin 1999). On the other hand, perhaps because these children are aware of their social limitations, they report feeling lonelier and having poorer quality friendships (Capps et al. 1996), than their typically developing classmates (Bauminger and Kasari 2000). They initiate and reciprocate peer interactions much less frequently than language-matched children with developmental disabilities (Hauck et al. 1995; Sigman and Ruskin 1999). In the absence of additional treatment, placement together with typically developing children has not been shown to increase social interaction (McConnell (2002).

Learning to make and keep friends may be especially difficult for the child with ASD, since the natural development and transmission of necessary peer etiquette requires generally positive and sustained interaction with peers and learning from best friends. Continued isolation makes deficits in the knowledge of peer etiquette more obvious as the child with ASD gets older. Not surprisingly, as adults, many individuals with ASD consequently lack community connections and friendships that are taken for granted by typically developing persons (Baxter 1997). Thus, teaching the skills necessary to make and keep friends has a significant life long impact for persons with ASD.

Best friendships among typically developing children become stable by about the fourth grade (Frankel 2010; McGuire and Weisz 1982). Having one or two best friends is of great importance to later adjustment, can buffer the impact of stressful events (Miller and Ingham 1976), correlates positively with self-esteem and negatively with anxious and depressive symptoms (Buhrmester 1990). In 
typically developing children, best friends may promote the development of social competence: while conflicts with acquaintances can decrease subsequent social interaction, conflicts among best friends and their resolution are associated with subsequent increases on measures of social problem solving (Nelson and Aboud 1985).

Sigman and Ruskin noted that only $27 \%$ of children with ASD had a best friend while this applied to $41 \%$ of children with other developmental disabilities. There is considerable interest among clinicians in how best to help these often highly motivated children with their social difficulties and best friendships.

Recently, Bauminger et al. (2008) have explored the best friendships of children with ASD. Although the sample was composed only of children who had at least one best friend and thus may not be representative of children with ASD, the results suggest that children with ASD may show greater social benefit from best friendships with typically developing children than with other children with disabilities. These "mixed" friendships were "...found to be more durable and stable and to exhibit higher levels of goal oriented social behaviors and positive affect. Friends in mixed dyads were more responsive to one another; showed higher levels of positive social orientation and cohesion, and demonstrated a more complex level of coordinated play than those in non-mixed dyads" (p.1224).

Much of the literature concerning difficulties of children with ASD specific to making friends has been based upon clinical observations and inferences from core deficits. Shaked and Yirmiya (2003) noted that children with ASD tend to have an egocentric conversational style characterized by difficulties in conversational reciprocity. Bauminger (2007) reviewed studies suggesting that initiating and sharing conversations are friendship skills deficient in children with ASD. Attwood (2000) noted that children with ASD have difficulties sharing interests or enjoyment with others as well as specific deficiencies in how they attempt to join a group of children already at play (cf., also Bauminger 2007). Prior et al. (1998) noted that some children with ASD try to make friends but in a clumsy manner that is generally unsuccessful. Attwood (2000) suggested that children with ASD lack what would be considered good host behavior on play dates, such as their inability to accept suggestions from their playmate, reciprocity and sharing with the play mate and conflict resolution skills.

The preponderance of research on social skills training for children with ASD has employed single case designs. Three recent reviews of this research have yielded different conclusions. Hwang and Hughes (2000) reviewed 16 studies which treated children across a wide range of functioning, including children with ASD who were nonverbal andlor echolalic. Programs were typically embedded in every day activities in more naturalistic situations including peer-mediated interventions, as opposed to teacher-directed discrete trial settings. Generalization was reported in many studies and follow-up also tended to report maintenance of treatment effects. But measures of outcome were generally limited to circumscribed target behaviors rather than to friendship skills.

McConnell (2002) developed a taxonomy of social skills interventions, dividing them into five categories: environmental modifications (physical and social environment), child-specific (training the child in specific skills), collateral skills (training play behaviors and language skills rather than direct training of specific skills), peer mediated (training non-disabled peers), and comprehensive interventions (combining two or more of these interventions). $\mathrm{He}$ used it to classify 55 studies of children with ASD, which included 157 participants younger than 9 years old. McConnell relied on the conclusions of investigators, and did not find differences in effectiveness between the different categories of interventions.

Bellini et al. (2007), focused upon school-based approaches, for children with ASD using a standard metric to measure outcome. Bellini et al. concluded that there was minimal evidence for effectiveness of social skills interventions for children with ASD.

Much of the literature on social skills training for children with ASD has focused on interventions with younger children in the lower ranges of social functioning (Wolfberg and Schuler 1993). Few social skills interventions have been devoted to investigating the efficacy of social skills training for children that are less socially impaired (Marriage et al. 1995). Among the social skills intervention studies conducted with this population, most have not been formally tested in terms of improving social competence or the development of close friendships. A notable exception was Ozonoff and Miller (1995), who taught five high functioning adolescents with ASD basic interaction and conversation skills and how to infer the mental states of others (Theory of Mind) over 14 sessions. Comparison with four non-treatment controls demonstrated significant improvement in false belief tasks in the treatment group only, but parent and teacher ratings of social competence did not improve. Moreover, the authors reported negative correlations between Theory of Mind scores and parent and teacher ratings of social skill.

Parent-assisted Children's Friendship Training (CFT, Frankel and Myatt 2003) contains modules that teach social etiquette and specific rules of behavior which are used by the peer group. This is a simple way for children with ASD to understand their social context. Targeted skills include conversational skills, peer entry, expanding and developing friendship networks, handling teasing, practicing good sportsmanship and good host behavior during play dates with friends. 
Parents may have significant effects upon their child's friendships, both in terms of direct instruction and supervision, as well as supporting their child's development of an appropriate peer network (Frankel and Myatt 2003). Parents are integrated into CFT within separate concurrent sessions. CFT addresses both a child's reputation in the peer group as well as the development of a best friend through parent-structured and supervised play dates with children not in the treatment group which emphasize selecting typically developing peers as potential playmates.

The effectiveness of CFT has been demonstrated for children with ADHD (Frankel et al. 1995; Frankel et al. 1997a, 1997b) and Fetal Alcohol Spectrum Disorders (O'Connor et al. 2006). Results of these studies suggest that skills generalize outside the treatment situation and are maintained at least three months after treatment ends. The present study was intended to test the following hypotheses:

(1) Children who participate in CFT will show greater mean gains in indices of social skills, than a Delayed Treatment Control (DTC) group at post-test.

(a) Child measures of popularity and loneliness will show significantly greater mean improvement for the CFT than for the DTC group from baseline to post testing.

(b) Parent measures of play date quality and social skills will show significantly greater mean improvement for the CFT than for the DTC group from baseline to post testing.

(c) Teacher measures of peer relationships will show significantly greater mean improvement for the CFT than for the DTC group from baseline to post testing.

(2) The CFT group will maintain improvement in indices of social skills after a 3 month follow-up period.

(a) Child measures of popularity and loneliness will maintain improvement for the CFT group after 3 months follow-up.

(b) Parent measures of play date quality and social skills will maintain improvement for the CFT group after 3 months follow-up.

(c) Teacher measures of peer relationships will maintain improvement for the CFT group after 3 months follow-up.

\section{Methods}

Participants

Participants were 58 boys and 10 girls recruited from September 2003 to March 2008. Sixty-one children were completely mainstreamed. Six children were in special education classes, but were included in a mainstreamed recess and mainstream classroom for part of the school day. One child was in a mainstream classroom with special help for 1-2 $\mathrm{h}$ a day to complete class work. Ethnic distribution for study children was 45 Caucasian, 10 Asian, 7 African American, 4 Hispanic, 1 Pacific Islander and 1 Native American. The university and the NIMH institutional review boards approved all procedures. Informed consent was obtained from parents and assent from children. All parent questionnaires were completed by the child's mother. Children were eligible for the study if they met all of the following inclusion criteria:

1. The child satisfied ADOS-G and ADI-R criteria for an Autism Spectrum Disorder (see below).

2. The child was currently attending a 2 nd through 5 th grade regular classroom for most of the school day without a "shadow" or other closely supervising adult. The age range was selected based in part upon previous clinical experience. Children who were younger than second graders were too overwhelmed by the didactic presentations to benefit. The local school systems usually grouped children past 5 th grade in middle school. In contrast to elementary school where usually one teacher saw a child throughout the day, middle schoolers were taught by several teachers. The range of grades was therefore restricted to elementary school since collection of outcome data from multiple teachers would pose logistic difficulties. The presence of a "shadow" or closely supervising adult might impact upon the treatment fidelity, since these adults would not be under the supervision of the present investigators and may introduce unknown additional intervention components for individual children in the study.

3. The child was not currently prescribed any psychotropic medication. A previous study (Frankel and Myatt 2007) suggested that psychotropic medication may mitigate the effects of treatment.

4. The child's Verbal IQ was greater than 60. This insured sufficient verbal ability so that the children could comfortably interact with other children in the classes.

5. The child was able to switch topics in a conversation when the other person was interested in talking about something else. Since the first modules taught children to select friends based upon common interests, this criterion ensured that the child had sufficient skill to determine another child's areas of interest. In essence this briefly assessed the child's capacity for joint attention and basic social reciprocity, which indicated readiness for the intervention. 
6. The child had adequate knowledge of rules in playing at least two common age-appropriate board games (e.g., checkers, chess, etc.). Since it was hypothesized that common interests and activities were fundamental to forming friendships, this criterion ensured that the child had sufficient play repertoire to engage with other children on play dates. CFT does not devote time to teach the rules of common games but helps parents intervene when their child doesn't abide by rules.

7. The child had knowledge of rules to play common school yard games (e.g., handball, kickball, four square, tetherball, jump rope, etc.). The rationale for this criterion was the same as criterion \#6.

8. Absence of a thought disorder

9. The child was free of clinical seizure disorder, gross neurologic disease, or other medical disorder (e.g., moderately impaired hearing, or severe uncorrectable visual impairment).

Criteria 5-8 were established during a child mental status exam (cf., Frankel and Myatt 2003).

\section{Measures}

Eligibility Measures

The High Functioning Autism Spectrum Screening Questionnaire (ASSQ; Ehlers et al. 1999) is a 27 item parent completed checklist. Items are rated on a 3-point scale $\quad(0=$ normality; $1=$ some abnormality; and 2 = definite abnormality). Ehlers et al. (1999) compared 21 children with autism spectrum disorders and 34 with Asperger Syndrome with 31 learning disabled, and 58 with ADHD. Test-retest reliability over a 2 week period was $r=.96$ for parents, and correlation between parent and teacher ratings was $r=.66$. This measure was used to screen potential study children entering an outpatient program for social skills training for inclusion in the present study. Children with scores greater than 21 were initiated into the study screening procedures.

The Autism Diagnostic Interview-Revised (ADI-R; Lord et al. 1994) is a standardized interview carried out with the parent or caregiver of the child. Diagnosis was determined by a well-validated algorithm consisting of a subset of questions combined into scores on the core domains. The broad spectrum ADI-R criteria utilized in the present study was more stringent than that proposed by Liu et al. (2001) and included children who met criteria for autism as well as those who were no more than 1 point away from meeting criteria for communication and/or social scales.

The Autism Diagnostic Observation Schedule -Generic (ADOS-G; Lord et al. 2000) is a semi structured observational instrument. All study staff administering the ADOS-G were trained by an ADOS trainer who was part of the Assessment Core of the UCLA Center for Autism Research and Treatment (CART). The ADOS-G trainer continued to participate in trainings regularly held by University of Michigan Autism and Communication Disorder Center (UMACC) to maintain reliability. ADOS-G administration was reviewed quarterly by the ADOS-G trainer. ADOS-G also coded ADOS-G tapes provided by UMACC to maintain training expertise and reliability. Reliability maintenance sessions were conducted every two months with each study staff and the ADOS trainer.

Wechsler Intelligence Scale for Children-3rd revision (WISC-III; Wechsler 1991) All children were administered all verbal subtests, which were used to derive the child's Verbal IQ.

\section{Descriptive Measures}

Vineland Adaptive Behavior Scales-Survey Form (VABS; Sparrow et al. 1984). The VABS was used to assess the level of adaptive behavior. Content validity has been established for each domain of the VABS (Sparrow et al. 1984). Raw scores were converted to standard scores $($ mean $=100, \mathrm{SD}=15)$.

Socioecenomic Status (SES, Hollingshead 1975). Parent SES was determined using this 4-factor algorithm combining level of education with occupation of parents.

\section{Child Outcome Measures}

The Loneliness Scale (Asher et al. 1984) is a child selfreport measure consisting of 16 statements such as "I feel left out of things at school", or "I get along with my classmates". Responses are recorded on a 5-point Likert scale indicating the veracity of the statement, ranging from "never" to "always". Summation of items yields a total loneliness score. Asher et al. (1984) reported high internal consistency (Cronbach's alpha $=.90$ ) and low to moderate correlations with sociometric status and best friend nominations (range was -.25 to $-.37, p$ 's $<.001$ ) for their sample of 506 3rd-6th graders. Bauminger and Kasari (2000) and Bauminger et al. (2003) found that children with ASD reported high levels of loneliness on this scale. However, this result has not always been replicated (Chamberlain et al. 2007).

Piers-Harris Self-Concept Scale (PHS, Piers 1984). The PHS is an 80-item yes-no self report measure that takes about 20 min for the child to complete. Piers (1984) provided factor scores on the six subscales. A global score is a composite of items from the self-esteem factors. The popularity subscale was used in the present study since it was most relevant to social outcome. It is composed of 12 
items which primarily measure the absence of self-evaluations of being rejected by peers (e.g., "I am left out of things") or being teased (e.g., "People pick on me"). Internal consistency of the Popularity subscale was reported as .74 (Piers 1984). The PHS has not been validated for children with ASD. Low self-esteem has been identified in children with ASD and has been related to parent ratings of social competence (Capps et al. (1996).

\section{Parent Outcome Measures}

Quality of Play Questionnaire-Parent (QPQ; Frankel and Mintz in press) is a measure of the quality of the last play date and the frequency of play dates. The administration of the QPQ begins by defining a play date as a oneon-one experience. Parents are asked to rate the last play date their child had with the peer invited over most often during the past month. Items 1-7 have parents rate the degree to which children engaged in different activities (1. Chasing, running...; 2. Cards or board games; 3 . Imaginary or pretend games; 4. Arts, crafts...; 5. Talk; 6. Computer or video games; 7. Watching TV or videos). Items 8-17 ask about negative interactions. These items are worded so as not to assign blame to a particular child for a negative interaction. Parents are required to make judgments of "Not at all" (0), "Just a little" (1), "Pretty much" (2), and "Very much" (3) for this play date. Item 18 asks parents to report the number of times their child was invited to another child's home as the only invited guest in the last month (Guest), and item 19 asked parents to report the number of times their child invited another child to their home as the only invited guest (Host) in the last month.

The Conflict scale was developed through factor analysis of 175 boys and girls (Frankel and Mintz in press). Coefficient alpha was .87. Convergent validity was demonstrated with the SSRS Problem Behaviors scale $(\rho=.35, p<.05)$. Conflict scores significantly discriminated a general community sample from children referred to social skills training $(p<.05)$. Host and Guest measures also significantly discriminated community-referred from clinic samples ( $p$ 's $<.005$, Frankel and Mintz in press). A cut point of 3.5 on the Conflict scale correctly classified $66.7 \%$ of clinic-referred and $72.3 \%$ of the community sample. A cut point of 2.5 for Guest resulted in correct classification of $66.7 \%$ of the clinic sample and $60.7 \%$ of the community sample. A cut point of 2.5 for Host resulted in correct classification of $66.7 \%$ of the clinic sample and $59.8 \%$ of the community sample. Laugeson et al. (2009) reported Spearman correlation between teens with ASD and parent ratings were .55 for the Conflict scale, .99 for Host, and .99 for Guest (deleting reports of " 0 " get-togethers resulted in correlations of .97 and .94 , respectively, all $p$ 's <.001). Frankel et al. (2010) reported significant correlations of Host, Guest, and Conflict with school playground observations of joint engagement with peers and positive peer responses to the initiations of the child with ASD. The importance of these measures as social outcome variables were suggested by previous research of fewer play dates for children with ASD (Sigman and Ruskin 1999) and by anecdotal reports from parents of conflict on play dates due to the child with ASD setting an inflexible agenda for a play date and arguing with his playmate if that playmate wouldn't comply with this agenda.

\section{Development of Play Date Activity Measures}

The QPQ contains activity items that have not been previously analyzed with respect to potential factors that they tap. These items may offer important information on the play dates of children with ASD as they may reflect the degree to which the child fills the play date with interactive as opposed to isolative activities, as reported by Bauminger et al. (2003). In order to reduce the number of variables for analysis, ratings of parents of children with ASD for the seven QPQ activity items were submitted to factor analyses. Departures from chance patterns in the scree plots of unrotated factors suggested two factors for rotation. An orthogonal solution was used, since a scale could be comprised of a summary score from each set of items. The two-factor solution accounted for $46.9 \%$ of the common variance. A cutoff loading of .55 was employed in order to reduce overlap between factor-based scales. The first factor ( 3 items) was labeled Engage, since it was composed of interactive items (1. Chasing, running; 3. Imaginary or pretend games; 5 . Talk). The second factor (3 items) was labeled Disengage, since it was composed of items that indicated minimal interactions (6. Computer or video games; 7. Watching TV or videos) and one interactive item (2. Cards or board games), which loaded negatively on this factor. Parent ratings for each item were summed to form the Engage and Disengage factor-based scales. Higher Engage scores indicated more time spent in interactive activities and higher Disengage scores indicated more time spent in minimally interactive activities. Coefficient alpha was calculated as .56 for the Engage factor-based scale and .49 for the Disengage factor-based scale.

Social Skills Rating System-Parent (SSRS; Gresham and Elliott 1990). The SSRS is a questionnaire consisting of 55 items rated as either "Never", "Sometimes", or "Very often" Among the seven subscales which compose this instrument, only assertion and self-control subscales of the Social Skills scale measured attributes relevant to friendships and only internalizing and externalizing behavior subscales measured behaviors applicable to 
children with ASD and are considered further. The assertion subscale measures making friends and playing well with them (10 items, e.g., "Makes friends easily"); the self-control subscale measures appropriate response to provocation by others (10 items, e.g., "Responds appropriately to teasing from friends or relatives of his or her own age"); the externalizing subscale measures intrusive and aggressive behavior (6 items, e.g., "Fights with others"), and internalizing measures social withdrawal (6 items, e.g., "Is easily embarrassed"). Raw scores were retained for all the subscales. Macintosh and Dissanayake (2006) compared children with either high functioning autism or Asperger's disorder on both the teacher and parent completed SSRS subscales. Correlations between teachers and parents exceeded $.31(p$ 's $<.01)$. Mean differences between children with ASD and typically developing children exceeded statistical significance at the $p<.001$ level for all scales used in the present study.

\section{Teacher Outcome Measures}

The Pupil Evaluation Inventory-Teacher (PEI; Pekarik et al. 1976) was composed of three scales, derived through factor analysis of peer ratings and validated against teacher and self ratings. The Withdrawal scale consists of nine items which assess shyness (e.g., "Those who are too shy to make friends easily") and sadness (e.g., "Those who never seem to have a good time"). The Likability scale consists of five items which assess highly prosocial behavior (e.g., "Those who are especially nice"). The Aggression scale originally consisted of 20 items. A revision of this scale was presented by Pope et al. (1991), who lengthened the instrument to 42 items and subdivided the Aggression scale into aggression, hyperactivity, and inattention subscales through factor analysis of peer ratings. The aggression subscale is composed of 10 items, which assess teasing and physical aggression (e.g., "Those who start a fight over nothing"). The Withdrawal scale and aggression subscale were retained for analysis as being most relevant to the sample. Alpha coefficients previously obtained were .69 for Withdrawal and .64 for the aggression subscale (Frankel et al. 1995).

In one study (Ledingham et al. 1982) teachers and students were asked to independently complete the PEI on all students in the class. Correlations between student and teacher ratings exceeded .54 on all scales. These scales have predictive validity. PEI assessments in first grade have been shown to predict antisocial behavior 7 years later (Tremblay et al. 1988) and to accurately classify peer acceptance (La Greca 1981; Ledingham 1981; Ledingham and Younger 1985). Badenes et al. (2000) have found small but statistically significant negative correlations between theory of mind tasks and aggression and withdrawal subscales in 4-6 year old peer-rejected children. However, validation studies of this measure for children with ASD have not been reported.

\section{Procedure}

Potential study children were referred from two sources: parents calling the UCLA outpatient clinic inquiring about the social skills program for their child, or parents evaluated by UCLA CART, Assessment and Evaluation Core whose child met diagnostic criteria for an Autism Spectrum Disorder with significant social problems. Parents were sent a packet of questionnaires to complete which included the ASSQ, SSRS and QPQ. Upon meeting preliminary screening criteria, and after obtaining parent consent and child assent, clinic referred children were given a diagnostic evaluation by CART, which included the ADOS-G, ADI-R, VABS and the WISC-III.

Upon meeting inclusion criteria, children were randomly assigned to receive 12 weeks of CFT immediately or after a 12 week delay (DTC). Study children were randomized as the screening was completed, using an online random number generator from Random.org. After an evaluation to determine if they met study criteria a random number between 1 and 2 was generated for each participant. If the value was 1 the participant was assigned to the CFT group and if the value was 2 the participant was assigned to the DTC group.

A 2-group CFT vs. DTC longitudinal design was used. Children and their parents in the CFT Group completed outcome measures just prior to receiving the intervention (T1), the last night of the intervention (T2), and 12 weeks after the conclusion of the intervention (T3), while DTC children and their parents completed outcome measures upon entering the study (T1), 12 weeks after $\mathrm{T} 1$ just prior to starting the intervention (T2), and the last night of the intervention (T3). Children and parents completed assessment measures in the presence of the research team, while teachers were mailed assessment measures at each of the testing periods.

\section{Treatment Content}

The CFT manual was developed for the mixed clinical sample seen through the UCLA Children's Friendship Program which, throughout its 18 year history, has included high functioning children with ASD. The treatment manual lists children with ASD as one of the common categories of children showing up for social skills training. Screening criteria 1-3 above were specifically developed to screen children with ASD who were likely to benefit from CFT. 
The CFT manual is based upon research that has demonstrated that child and parent behaviors within certain critical situations discriminate socially accepted from rejected children. These critical situations are: (1) social network formation with the aid of the parent (Parke et al. 1994); (2) informational exchange which explores mutual interests with peers leading to common-ground activities (Black and Hazen 1990); (3) entry into a group of children already at play (Frankel 2005); (4) in-home play dates (Frankel 2010); and (5) conflict avoidance and negotiation (Rose and Asher 1999). The key features of CFT were taught through instruction on simple rules of social behavior; modeling, rehearsal, and performance feedback during treatment sessions; rehearsal at home; homework assignments; and coaching by parents during play with a peer (Elliot and Gresham 1993). The CFT manual has been successfully implemented for children between the ages of 6 and 12 years in multiple clinical contexts (Frankel and Myatt 2007; Frankel et al. 1997b; Frankel et al. 1999; O'Connor et al. 2006) and by clinicians with no connection to the present authors (Sim et al. 2006).

The CFT manual format (Frankel and Myatt 2003) reviewed the research base for the development of each module. It gave a step by step outline of how to run screening, intake, each treatment session and homework assignment of the intervention. It provided all necessary parent handouts and child session plans. It gave short vignettes of the effects of typical session components as well as many vignettes on common problematic encounters and suggested how group leaders should respond to these challenges. Two intake and 19 session vignettes presented in the manual specifically pertain to children with ASD.

CFT (and DTC children after T2) were integrated into classes being conducted by the UCLA Children's Friendship Program, with no more than 4 children with ASD admitted to any class (class size was usually 10). The nonASD children were seeking clinical treatment on a fee for service basis and also met the inclusion criteria 2 through 9. Chart diagnoses for these children were Adjustment Disorder (18.6\%), ADHD (46.0\%), ADHD and Oppositional Defiant Disorder (ODD, 2.7\%), ODD alone (0.5\%), Fetal Alcohol Spectrum Disorder (0.7\%), anxiety disorder (4.9\%), mood disorder (1.3\%), learning disability $(1.3 \%)$ and $25.2 \%$ had no diagnosis. The mixing of children with and without ASD was done to provide peers who were more typically developing and could offer realistic practice for the skills being taught, as the aim of the program was to integrate children with ASD into groups of typically developing peers. Each CFT class was composed of children separated by no more than one grade level. Study children were not identified in any way to other class participants.
Treatment was composed of 12 weekly sessions, of $60 \mathrm{~min}$ in length. Children and their parents were seen concurrently in separate locations (except for the finalization of the child's homework assignment). Each child session (except for the first and last) was composed of four segments. During the first segment $(10 \mathrm{~min})$ children reported the results of the homework assignment given in the previous session. The second segment (20 min) consisted of a didactic presentation and brief, coached behavioral rehearsal between children. The third segment (25 min) consisted of coached play in which children practiced newly learned skills. In the fourth segment (5 min), parents and children were reunited and contracts for homework were finalized.

Formal parent sessions were held concurrently for the entire hour of all child sessions. Session 1 was devoted to parent orientation (with an accompanying handout) and arrangements for calling other class members to practice conversational skills. Sessions 2-11 were broken into four segments. During the first segment $(15 \mathrm{~min})$, the group leader reviewed parent and child performance on the previous socialization homework assignment. During the next segment (30 min), a parent handout was reviewed with the parents and relevant questions were answered. In the third segment $(10 \mathrm{~min})$, the next socialization homework assignment was presented and specific problems anticipated by the parent were discussed. During the last segment (5 min), parents and children were reunited and verbal contracts were made for completion of the next socialization homework assignment.

Children were taught conversational techniques (voice volume, smile, physical closeness) and were instructed on how to "play detective" as an information sharing and query technique with other class members in order to plan future play. They also rehearsed calling up another class member on the telephone. Children were instructed on good and bad times and places to make friends, how to watch a group of children in play in order to understand what the group was doing, and what the rules were to participate. They were also coached to make relevant comments or praise the children who were playing (e.g., "good shot"), and to join the play by "helping them play their game". Children were cautioned not to ask questions, mention themselves or their feelings, disagree with, or criticize the children playing the game. Children were told to expect $50 \%$ rejection in their attempts to enter the playing groups. Reasons for rejection were discussed as well as what to do in each case. They were instructed on how to avoid criticizing others and to let others have fun (i.e., let them catch the ball too). Emphasis was placed on "helping others play" rather than "winning at all costs". Techniques of persuasion and negotiation were taught to allow subjects to change activities when they lost interest. 
The "rules for a good host", were presented in order for children to avoid conflict on play dates: (a) The guest is always right (s/he gets to pick the games, take turns, etc.); (b) Praise the guest's behavior (e.g., "nice try", "great shot"); (c) No criticism of the guest; (d) If you're bored, make a deal with the guest to change the game; and (e) Be loyal to your guest (play dates were to be with only one guest at a time, who was not to be left alone). Children were paired together to practice being a good host during pretend play dates (i.e., one was the "host" and one was the "guest" in each pair).

Children were taught to respond neutrally or humorously to teasing in the following manner: The group leader modeled how to "make fun of the teasing" so that the perpetrator was teased about their inability to tease well (e.g., "I've heard that one before", "Tell me when you get to the funny part"). Subjects practiced "making fun of the teasing" in response to a structured teasing exercise from the group leader using benign teasing comments.

Socialization homework assignments were key to obtaining generalization. No assignment was made until its contents were practiced in the child sessions and presented within a handout to parents. The first segment of each parent session was especially critical as parents were asked to recount the events of the homework assignment for the previous week. Thus, after a play date homework assignment, parents described the major events of the play date. Any barriers to organizing a successful play date were discussed and suggestions were made to overcome these barriers.

Socialization homework assignments were as follows: (a) Children were to call another member of the class (at first, and in later sessions another child in their community with whom they wanted to be friends) in order to practice information sharing and query. During a CFT session, parents were to arrange the day and time of the call and at the appointed time, were to listen in on the call. (b) Children were instructed to bring a nonviolent, interactive toy from home to all sessions to be used during play activities. Group leaders inspected these toys for appropriateness prior to allowing them into the child session. (c) Children were to practice joining a group of children at play in their local community. In order to increase their chances of gaining entry, they were encouraged to approach slightly younger children with whom they were unfamiliar. Parents were to help their child decide where and when this would be attempted. The parent was instructed to let the child try this by him/herself as unobtrusively as possible. (d) Parents were provided with a handout listing the specific steps to organizing and implementing a play date (Frankel and Myatt 2003, p.132). The first step was to agree on a potential play mate they would like to invite over to their home for 1-2 h. Social contacts with class members outside the class were prohibited, so that this potential play mate had to be a child who was not a member of the CFT intervention. The study child was to call this child and "play detective" in order to generate a list of possible games to play. The parent was to check with the invited child's parent to arrange the date, time and length of the play date. During the play date, the parent was to listen for violations of any good host rule and to step in and remind their child of these rules when they were broken. (e) Children were to practice "making fun of the teasing" with a child who was teasing them. (f) The final session included a handout on maintenance of treatment gains which focused upon maintaining weekly one-on-one play dates with other children.

\section{Common Problems Posed by Children with ASD}

Children with ASD share many friendship problems in common with children without ASD. In addition, children with ASD posed unique problems in understanding and completing four homework assignments given as part of CFT:

(a). Bringing in interactive toys from home. Children with ASD sometimes brought inappropriate toys to fulfill this assignment. Examples were a Frisbee the child's dog chewed up, a wood board crudely broken into 2 pieces for "game play", objects that were not conducive to sustained interaction with age mates, such as stuffed animals, balloons and magic tricks. Group leaders prevented the children from taking these toys into session and guided parents to have the children bring more appropriate interactive toys to fulfill future assignments.

(b). Practicing information sharing and query with another child on a phone call prearranged by the parents. Some children with ASD were nervous about making this phone call. Some children with ASD (sometimes encouraged by parents) made a list of questions prior to the call that they then read over the phone. This resulted in the children asking the next question on their list as soon as the previous question was answered, not listening to the answers offered by the other child. Some children with ASD have taken the suggested length of the call (about $10 \mathrm{~min}$ ) too literally and abruptly hung up when the 10 min mark was reached. In all of these cases, the parent group leader helped parents implement practice sessions with their child immediately before the homework assignment was to be done. The parent was advised to role play the call, pretending to be the other child. Specific guidance was provided the parent on promoting spontaneity, eliminating the list 
of questions and waiting for a longer pause in the conversation as a cue to provide a pre-rehearsed cover story to end the call (e.g., "I have to eat dinner now...")

(c). Arranging and carrying out play dates with neighborhood children. Some children with ASD were initially nervous with regard to inviting playmates for play dates. This was addressed by lowering expectations for early play dates (e.g., inviting a long-time friend or cousin over for the first play date) and gradually moving onto new children the child would like to be friends with. More serious problems were posed by the child with no play date possibilities, for instance a child with no current sources of potential new friends and perhaps a negative reputation at school. The intake staff attempted to prevent this situation by having parent search for and enroll their child in new activities prior to the start of the CFT class.

(d). Making fun of the teasing. Children with ASD tended to have the poorest and least effective defenses against being teased. They tended to use silly or nonsensical comebacks. Children with ASD were taught to use simple comebacks involving very few words (e.g., exaggerated yawn, or saying "Boo Hoo" with flat affect and exaggerated rubbing of one eye with fist) and discouraged from making, long, complicated, or silly responses.

\section{Treatment Integrity}

Repeating an intervention for numerous treatment groups over a period of 5 years poses a challenge to treatment fidelity. Group leaders may be prone to "clinician drift" in which they subtly modify the treatment over successive iterations. In order to address this issue, treatment fidelity was maintained in three ways, suggested by Moncher and Prinz (1991): (1) The child group leader was a Ph.D. level psychologist (author RM) with over 10 years of experience in social skills training. The parent group leader (author CW) was an L.C.S.W. with over 5 years of experience in social skills training. (2) A manual was developed and followed which detailed the curriculum for each parent and child session. The group leaders began each topic by reading from the manual. (3) Fidelity checklists covering the primary content of the protocol were created for each treatment session. Undergraduate psychology students were provided with a checklist for each session, and verified that each topic in the manual was reviewed and that no other topics were presented other than those in the manual. If a group leader failed to cover any primary content, the undergraduate fidelity assessor reminded them during the session.

\section{Power Analysis}

The SSRS social skills subscales were selected as the primary measure for the present study. Previous research in this setting obtained effect sizes of 1.1 and 1.34 for children with ADHD prescribed stimulant medication (Frankel et al. 1997a) and with the total Social Skills scale obtained an effect size of 1.15 for children with Fetal Alcohol Spectrum Disorders (O'Connor et al. 2006). Effect size was conservatively estimated at .65 (half the average of these effects sizes). With 40 children in one group and 36 in the other, a two sample $t$-test has about $80 \%$ power to detect a difference between groups of $d=.65$ or $2 / 3$ of a standard deviation, slightly above the conventional medium effect of $d=.5$ using the standards of Cohen (1988). For the within group change between time points there is an $89 \%$ (for the group of 40) and $85 \%$ (for the group of 36) power to detect a medium effect of $d=.5$. Attrition from the original recruitment targets was compensated for in the primary analysis by the use of baseline scores as covariates which tends to significantly increase power.

\section{Results}

\section{Participant Attrition}

A total of 76 children met final eligibility requirements and all families agreed to participate. Forty children were assigned to the CFT condition and 36 were assigned to the DTC condition. Of that number, 8 children did not complete T2 assessments: Two children in the CFT condition were removed from the study for severe behavioral problems during treatment sessions and referred elsewhere, 3 children in the CFT condition discontinued attending on or before completing 3 sessions, 1 child in the DTC condition participated in a conflicting activity which precluded participation in the present study, and 2 children in the DTC condition did not return for $\mathrm{T} 2$ assessments for unknown reasons.

At the conclusion of the study, 26 of the remaining 35 children in the CFT condition $(72.2 \%)$ completed the T3 assessment. In the DTC condition, 31 of the remaining 33 children of the children $(93.9 \%)$ completed the T3 assessment following CFT training. Teacher data was obtained at $\mathrm{T} 1$ and $\mathrm{T} 2$ for 31 children in the CFT condition $(86.1 \%)$ and 28 children in the DTC condition (84.8\%). All children remaining in the study at $\mathrm{T} 3$ had teacher data.

\section{Baseline Comparison of CFT vs. DTC}

Table 1 presents the mean demographic variables for each group. $T$-tests for age, grade, SES, WISC-III Verbal IQ, 
Table 1 Sample characteristics for children's friendship training (CFT) and delayed treatment control (DTC) conditions

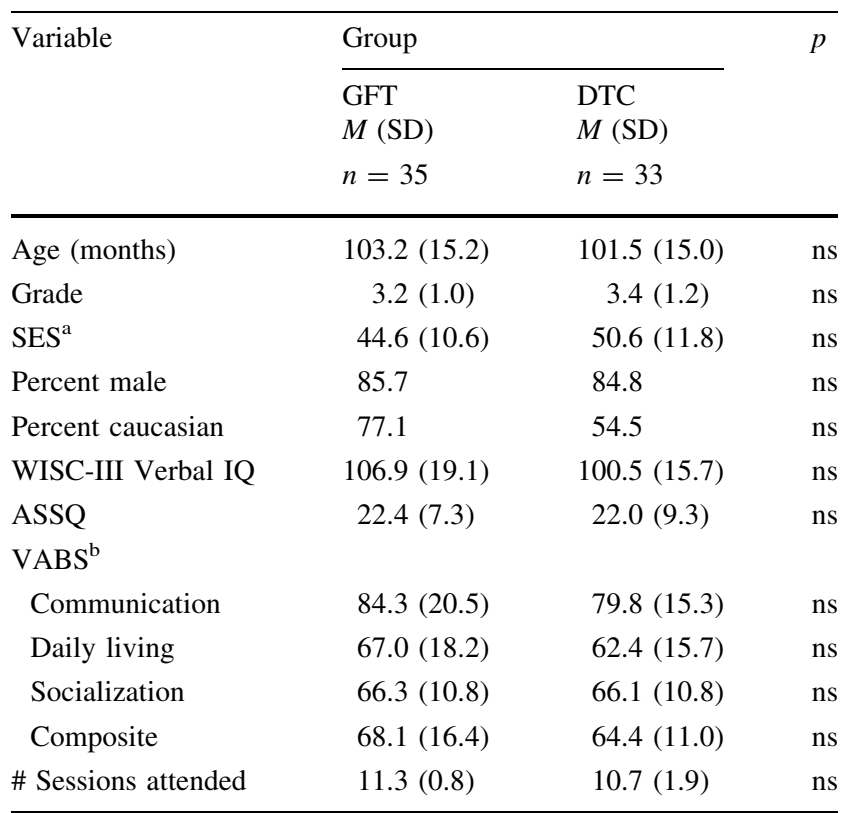

${ }^{\mathrm{a}}$ DTC $n=32$

${ }^{\mathrm{b}}$ CFT $n=34$

ASSQ, VABS subscales and number of sessions attended (applying to the CFT group between $\mathrm{T} 1$ and $\mathrm{T} 2$ and the DTC group between T2 and T3) all failed to reach significance ( $p$ 's $>.12)$. Chi-Square tests for percent male and percent Caucasian also failed to reach significance $(p$ 's $>.10)$. Mean T1 scores on each outcome variable are presented in Table 2 . No baseline scores were significantly different between groups ( $p$ 's $>.13$ ). Demographic and baseline outcome variables were also compared for children who persisted through T2 $(n=68)$ and those who did not $(n=8)$, as well as those with teacher completed PEI's on T1 and T2 versus those who did not ( $n ' s=58$ and 9, respectively). Results for the analysis of study persisters revealed no significant differences from those who dropped ( $p$ 's > .12). Results of the analysis for missing teacher data revealed that children with missing teacher data had significantly higher mean baseline SSRS externalizing scores $($ Mean $=7.0$, S.D. $=2.6)$ than children with completed teacher reports $($ Mean $=4.7$, S.D. $=2.3 ; t(65)=2.86$, $p<.01$; all other $p$ 's $>.11$ ).

\section{Outcome Comparison of CFT to DTC}

The short-term efficacy of the treatment was evaluated with separate analyses of covariance (ANCOVA), performed at the group level, using post treatment (T2) scores as the dependent variable. Treatment (CFT versus DTC) was the grouping factor, and baseline scores (T1) for each variable was used as the covariate. Table 2 shows the results of these analyses. Five of the 13 analyses were statistically significant and four were marginally significant $(p<.07)$.

Children in the CFT condition reported significantly improved mean Loneliness scale scores $[F(1,64)=6.85$, $p<.025]$, and popularity subscale scores $[F(1,65)=5.42$, $p<.025]$ when compared the children in the DTC condition. Analyses of play date measures revealed statistically significant condition effects for Host $[F(1,61)=25.29$, $p<.0001]$, Disengage $[F(1,59)=28.08, p<.0001]$ and marginally significant effects for Conflict $[F(1,59)=3.44$, $p=.069]$. Due to the absence of hosted play dates at baseline for some children, parents were not able to provide Conflict, Engaged and Disengaged ratings. Parents of children in the CFT condition reported significant increases in the number of hosted play dates and decreased disengaged behaviors on play dates when compared to the DTC condition. On the SSRS, parents of children in the CFT condition reported significantly improved self-control, and marginally significant assertion, internalizing and externalizing subscale scores when compared to parents of children in the DTC condition $[F(1,65)=5.06,3.86,3.73$, and 3.60 , $p ' s=<.05, .054=.058$ and $=.062$, respectively]. No teacher reported scales reached significance $(p$ 's $>.13)$.

\section{CFT Treatment Effects at 3-month Follow Up}

The effect of treatment on outcome variables at 3-month follow up was evaluated with two-tailed pairwise $t$-tests (T2-T3 and T1-T3) on the scores of children in the CFT condition. The DTC group received treatment during this time period, so it could not be used as a comparison group. The dependent variables were change scores across two time periods: baseline to 3 month follow up (T1-T3) to reflect net improvement at 3-month follow-up over baseline values, and post treatment to 3-month follow up (T2-T3) reflecting the degree of reversal of post test scores back to baseline. Table 3 presents the results of these analyses.

Results of the T1-T3 analyses indicated that gains were not maintained for either child measures $(p$ 's $>.14)$ or teacher measures ( $p$ 's $>.23$ ), but all of the parent measures that reached or trended towards significance at $\mathrm{T} 2$ showed significant gains at T3 (T1-T3: Host, $t(25)=2.27$, $p<.05$; Conflict, $t(25)=4.21, p<.0005$; Disengage, $t(25)=2.95, p<.025$; assertion, $t(25)=4.90, p<0001$; self-control, $t(25)=3.22, p<.005 ;$ and internalizing, $t(25)=2.41, p<.025)$. The one exception to this was the significant reversal from $\mathrm{T} 2$ to $\mathrm{T} 3$ for Disengage $(t(25)=5.08, p<.0001)$.

\section{DTC Treatment Outcomes}

The effect of treatment on outcome variables for the DTC group was evaluated with two-tailed pairwise $t$-tests 
Table 2 Comparison of children's friendship training (CFT) to delayed treatment control (DTC)
${ }^{a}$ N's were 32 for DTC group

b N's were 27 for DTC group

* $p$-values are for a group difference at time $\mathrm{T} 2$ after adjusting for $\mathrm{T} 1$ values

\begin{tabular}{|c|c|c|c|c|c|}
\hline \multirow[b]{2}{*}{ Variables } & \multicolumn{2}{|l|}{$\mathrm{T} 1$} & \multicolumn{2}{|l|}{$\mathrm{T} 2$} & \multirow[t]{2}{*}{$p^{*}$} \\
\hline & $\begin{array}{l}\mathrm{CFT} \\
M(\mathrm{SD}) \\
n=33\end{array}$ & $\begin{array}{l}\mathrm{DTC} \\
M(\mathrm{SD}) \\
n=35\end{array}$ & $\begin{array}{l}\mathrm{CFT} \\
M(\mathrm{SD}) \\
n=33\end{array}$ & $\begin{array}{l}\text { DTC } \\
\text { M (SD) } \\
n=35\end{array}$ & \\
\hline \multicolumn{6}{|l|}{ Child measures } \\
\hline Loneliness $^{\mathrm{a}}$ & $34.3(12.3)$ & $37.8(14.3)$ & $31.4(8.5)$ & $38.9(13.3)$ & $<.025$ \\
\hline Popularity & $7.2(3.0)$ & $6.8(3.0)$ & $8.0(2.8)$ & $6.4(2.9)$ & $<.025$ \\
\hline$n$ & 35 & 33 & 35 & 33 & \\
\hline \multicolumn{6}{|l|}{ Parent measures } \\
\hline \multicolumn{6}{|l|}{ QPQ } \\
\hline Host & $2.4(2.2)$ & $1.8(2.3)$ & $3.7(1.7)$ & $1.4(2.0)$ & $<.0001$ \\
\hline Guest & $1.3(1.6)$ & $1.1(2.0$ & $2.0(2.5)$ & $1.2(1.5)$ & ns \\
\hline Conflict $^{\mathrm{b}}$ & $4.8(4.2)$ & $5.1(5.2)$ & $1.9(2.8)$ & $3.3(3.2)$ & $=.069$ \\
\hline Engage $^{\mathrm{b}}$ & $4.2(2.2)$ & $4.3(2.1)$ & $4.7(2.2)$ & $4.3(1.7)$ & ns \\
\hline Disengage $^{\mathrm{b}}$ & $5.2(2.5)$ & $5.2(2.2)$ & $2.3(1.7)$ & $4.8(2.1)$ & $<.0001$ \\
\hline$n$ & 35 & 29 & 35 & 29 & \\
\hline \multicolumn{6}{|l|}{ SSRS } \\
\hline Assertion & $9.5(2.8)$ & $9.4(3.4)$ & $11.8(3.2)$ & $10.5(3.2)$ & $=.054$ \\
\hline Self-control & $10.2(3.4)$ & $9.0(3.9)$ & $12.2(2.9)$ & $10.1(3.7)$ & $<.05$ \\
\hline Externalizing & $4.5(2.6)$ & $5.4(2.3)$ & $3.8(2.1)$ & $5.2(2.3)$ & $=.062$ \\
\hline Internalizing & $7.0(1.7)$ & $7.2(3.2)$ & $6.4(2.1)$ & $7.3(2.5)$ & $=.058$ \\
\hline$n$ & 35 & 33 & 35 & 33 & \\
\hline \multicolumn{6}{|c|}{ Teacher measures } \\
\hline \multicolumn{6}{|l|}{ PEI } \\
\hline Withdrawal & $4.0(2.1)$ & $3.8(2.1)$ & $3.6(2.4)$ & $3.7(2.1)$ & ns \\
\hline Aggression & $1.3(1.7)$ & $1.4(1.8)$ & $1.0(1.3)$ & $1.4(2.0)$ & ns \\
\hline$n$ & 31 & 28 & 31 & 28 & \\
\hline
\end{tabular}

(T2-T3). The immediate outcome of children in the DTC group showed a pattern of significance for outcome variables similar to these depicted in Table 2 except that most outcome variables reached significance [Loneliness, $t(30)=2.69$, $p<.025$; Host, $t(28)=3.41, p<.002$; Conflict, $t(27)=$ $3.85, \quad p<.001 ;$ Disengaged, $t(28)=5.32, \quad p<.0001$; assertion, $t(30)=4.33, p<0002$; self-control, $t(30)=$ $3.08, \quad p<.005$; externalizing, $t(30)=3.70, \quad \mathrm{p}<.001$; internalizing, $t(30)=3.11, p<.005]$. Popularity obtained marginal significance $[t(30)=1.91, p=.065]$. Guest, Engaged and teacher reported outcome variables failed to reach significance ( $p$ 's $>.17)$.

\section{Post-hoc Analyses of Reliable Change}

This post-hoc analysis was intended to determine the numbers of children demonstrating reliable change on each outcome measure. Following the approach in Jacobson and Truax (1991) for each measure and pair of time points, reliable change scores were computed for each subject as $\mathrm{RC}=(\mathrm{x} 2-\mathrm{x} 1) / \mathrm{se} \cdot \mathrm{rc}=(\mathrm{x} 2-\times 1) \mathrm{sd} 1 * \operatorname{sqrt}(2(1-$ reliability)) where the numerator was the raw change for the subject, sd1 was the standard deviation of the measure at baseline and the reliability measure was Cronbach's alpha (the recommended choice from a psychometric perspective), except in the case of QPQ Host and QPQ Guest where the scales do not have multiple items. In these cases the test-retest correlation for the DTC group between T1 and T2 was used. The higher the RC index, the more the subject had changed relative to the internal variability of the measure and hence the more reliable was that change. A change of 2 RC units ( $2 *$ se.rc) has been frequently used as a standard of reliable change in analogy with 2 Standard Errors being a significant group difference. The results of this analysis are presented in Fig. 1 for the child variables, Fig. 2 for the play date variables and Fig. 3 for the SSRS variables. For each outcome variable, entries for CFT T1-T2 and DTC T1-T2 contrast treatment and control conditions. The entry for DTC T2-T3 represents the period when the DTC group received CFT and serves as a replication of the CFT T1-T2 entry. The number of children with changes between 1.5 and $2 \mathrm{RC}$ units and more than 2 $\mathrm{RC}$ units are presented in the figures to illustrate that, in addition to those who met the classical threshold, there were many more children than would expected by chance who were very close to the threshold. 
Table 3 Comparison of intervention to follow-up phase for all subjects in the CFT group

\begin{tabular}{|c|c|c|c|c|c|}
\hline Variables & $\begin{array}{l}\mathrm{T} 1 \\
M(\mathrm{SD}) \\
n=26\end{array}$ & $\begin{array}{l}\mathrm{T} 2 \\
M(\mathrm{SD}) \\
n=26\end{array}$ & $\begin{array}{l}\mathrm{T} 3 \\
M(\mathrm{SD}) \\
n=26\end{array}$ & $p(\mathrm{~T} 1-\mathrm{T} 3)$ & $p(\mathrm{~T} 2-\mathrm{T} 3)$ \\
\hline \multicolumn{6}{|l|}{ Child measures } \\
\hline Loneliness & $36.3(12.2)$ & $31.6(8.1)$ & $33.0(13.7)$ & ns & ns \\
\hline Popularity & $6.9(3.0)$ & $7.9(2.7)$ & $7.4(2.8)$ & ns & ns \\
\hline \multicolumn{6}{|c|}{ Parent measures } \\
\hline \multicolumn{6}{|l|}{ QPQ } \\
\hline Host & $2.0(2.1)$ & $4.0(1.6)$ & $3.1(2.9)$ & ns & $<.05$ \\
\hline Guest & $1.4(1.7)$ & $1.8(2.6)$ & $1.9(1.5)$ & ns & ns \\
\hline Conflict & $4.3(3.3)$ & $1.8(3.0)$ & $2.0(2.6)$ & ns & $<.0005$ \\
\hline Engage & $3.8(2.1)$ & $4.5(2.2)$ & $4.2(2.0)$ & ns & ns \\
\hline Disengage & $5.2(2.3)$ & $2.1(1.6)$ & $4.1(2.2)$ & $<.0001$ & $<.025$ \\
\hline \multicolumn{6}{|l|}{ SSRS } \\
\hline Assertion & $9.7(2.8)$ & $11.7(2.8)$ & $12.0(3.5)$ & ns & $<.0001$ \\
\hline Self control & $9.8(3.5)$ & $12.0(2.8)$ & $11.8(3.8)$ & ns & $<.005$ \\
\hline Externalizing & $4.5(2.4)$ & $3.8(2.0)$ & $3.8(2.5)$ & ns & ns \\
\hline Internalizing & $7.1(1.6)$ & $6.2(1.7)$ & $6.0(2.5)$ & ns & $<.025$ \\
\hline \multicolumn{6}{|c|}{ Teacher measures ${ }^{a}$} \\
\hline \multicolumn{6}{|l|}{ PEI } \\
\hline Withdrawal & $4.2(2.2)$ & $3.5(2.5)$ & $3.6(2.8)$ & ns & ns \\
\hline Agression & $1.5(1.8)$ & $1.3(1.3)$ & $1.6(1.7)$ & ns & ns \\
\hline
\end{tabular}

${ }^{\text {a }} n=24$

In general, Figs. 1-3 illustrate that from $\mathrm{T} 1$ to $\mathrm{T} 2$ the differences between the CFT and DTC groups were driven by a larger number of "improvers" in the CFT group (usually more than double) than the DTC group. The DTC group from T2 to T3, which was their treatment period, showed similar gains to the CFT group from $\mathrm{T} 1$ to $\mathrm{T} 2$. It should be noted that for the child measures of loneliness and popularity (cf., Fig. 1), the observed group differences

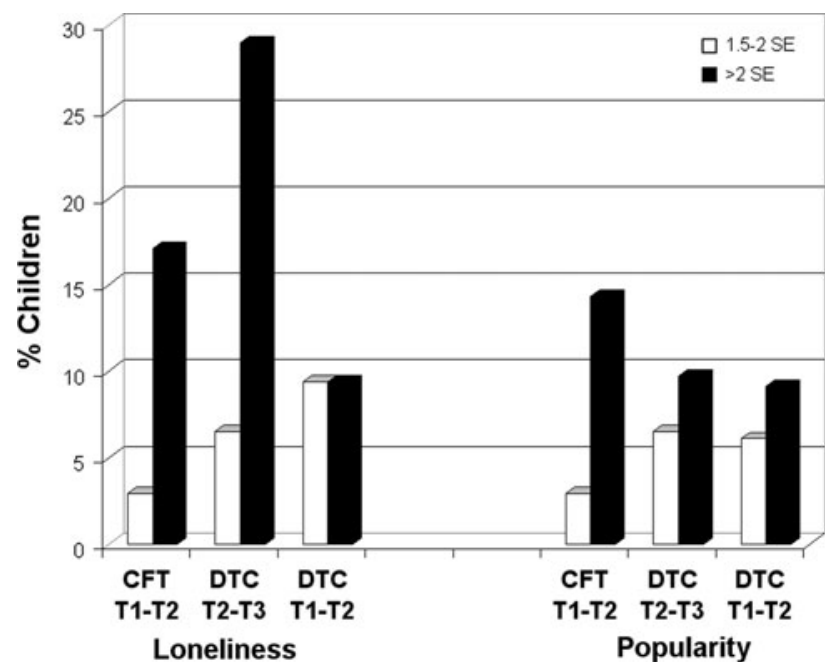

Fig. 1 Percentage of children exceeding reliable change ( $>2$ SEs) or close to this threshold (1.5-2 SEs) after receiving CFT (CFT T1-T2 and DTC T2-T3) or waiting for treatment (DTC T1-T2) for child completed measures of loneliness and popularity were also driven in part by greater percentages of children in the DTC group worsening than in the CFT group. Thus in Fig. 1, the percentage of improvers in popularity during the wait period (DTC T1-T2) did not appear different than those after receiving treatment. The DTC group from T2 to T3 generally replicated the effects noted in the CFT group

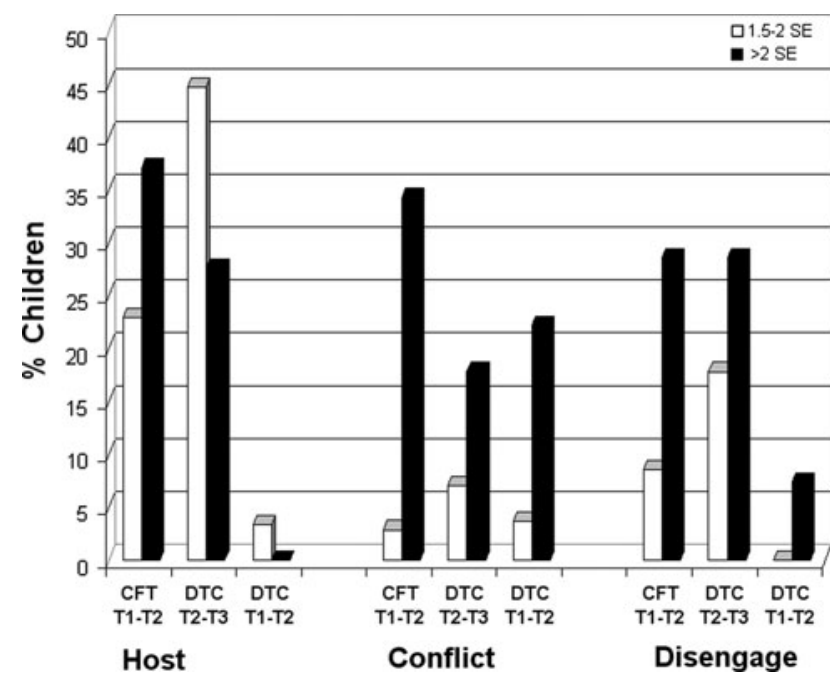

Fig. 2 Percentage of children exceeding reliable change ( $>2$ SEs) or close to this threshold (1.5-2 SEs) after receiving CFT (CFT T1-T2 and DTC T2-T3) or waiting for treatment (DTC T1-T2) for Host, Conflict, and Disengage parent rated subscales of the Quality of Play Questionnaire 


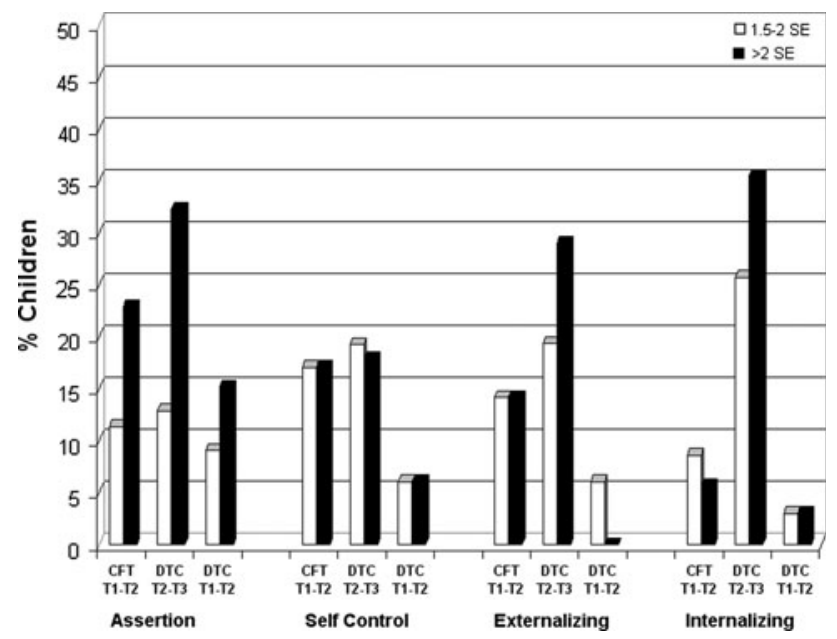

Fig. 3 Percentage of children exceeding reliable change ( $>2$ SEs) or close to this threshold (1.5-2 SEs) after receiving CFT (CFT T1-T2 and DTC T2-T3) or waiting for treatment (DTC T1-T2) for Assertion, Self-Control, Externalizing and Internalizing subscales of the parent rated Social Skills Rating Scale

from T1 to T2, with the sole exception of the Conflict scale (Fig. 2).

Another indicator of the magnitude of change was on how many outcome measures did each child show reliable change (i.e., greater than 2 Standard Errors from baseline). This is presented in Table 4. Evident from the table was that the distributions of children demonstrating reliable change were similar immediately after the treatment period for both CFT and DTC groups. A small minority of children ( 3 for the CFT group T1-T2 and 4 for the DTC group T2-T3) failed to show reliable change on any measure. Most (91.4\% for CFT and $87.1 \%$ for DTC) showed reliable change on at least one outcome measure immediately after the end of treatment. Furthermore, even at follow-up (CFT T1-T3) $66.7 \%$ of children continued to show reliable change on at least one outcome measure (18/27 children).

Table 4 Numbers of subjects showing reliable change ( $>2$ SD) for each group at each time point

Group time Number of outcome measures showing reliable change

\begin{tabular}{llllllllll} 
& & 0 & 1 & 2 & 3 & 4 & 5 & 6 & Total \\
\hline CFT & T1-T2 & 3 & 11 & 7 & 5 & 6 & 2 & 1 & 35 \\
DTC & T2-T3 $^{\mathrm{a}}$ & 4 & 11 & 5 & 4 & 3 & 2 & 0 & 31 \\
CFT & T1-T3 $^{\mathrm{b}}$ & 9 & 6 & 4 & 2 & 4 & 1 & 1 & 27 \\
\hline
\end{tabular}

${ }^{a}$ Two subjects were missing T3 data (not included in table)

b Eight subjects were missing T3 data (not included in table) and one subject had only teacher data for T3

CFT T1-T2 and DTC T2-T3 are at post-treatment and CFT T1-T3 is at 3-month follow-up

\section{Discussion}

This study compared the immediate outcome of parentassisted Children's Friendship Training with a delayed treatment control. The study also followed the CFT group 3 months after treatment concluded. The sample was composed of children rigorously diagnosed with ASD. Outcome measures represented ratings by the child, the parent and the child's teacher. Many of the modules of CFT have been validated as important in friendship formation, but not specifically for children with ASD.

The results demonstrated modest group effects at posttesting (T2) for CFT group when compared to the DTC group. Five of 13 outcome measures showed significantly greater improvement for children in the CFT group when compared to children in the DTC condition. Four other measures showed marginally significantly greater improvement for CFT when compared to DTC. The brief 12 week program tested in the present study was associated with modest gains in parent reported measures of the number of hosted play dates and decreases in proportion of time on these play dates that were filled with computer, videogames and television. This is important as many of the parents of children who had play dates would report these would be filled almost exclusively with electronic media with little evidence of social interaction. Post-hoc analysis revealed that between 10 and 13 children showed reliable change on these variables. Parents in the CFT group also rated their children as having more self-control and marginally improved in assertiveness, decreased conflict on play dates, internalizing and externalizing symptoms. The children reported improved perceptions of popularity and decreased perceptions of loneliness. Thus Hypotheses 1 (a) for child measures and 1(b) for parent measures received some support. But Hypothesis 1(c) was not supported for immediate outcome of teacher reports. In what may be viewed as a replication of the results, analysis of outcome for the DTC group from T2 to T3, after they finally received the intervention, was generally consistent with the results of the CFT group.

Unfortunately the DTC group could not be used to evaluate the follow up period, as our previous clinical experience suggested that substantial numbers of children would have found treatment elsewhere before T3 measures could be taken. The results of the analysis of follow-up data demonstrated weaker effects of treatment. Children in the CFT group maintained improvement on six of nine parent measures, with between 1 and 7 children showing reliable change on each measure. But none of the child or teacher measures demonstrated significant differences from baseline. Parents reported significantly more hosted play dates with less conflict and disengaged behavior in addition to less internalizing behavior in comparison to baseline 
levels. However, by the end of follow-up, on average children had returned to more solitary behavior on play dates. Thus Hypotheses (b) for longer term outcome for almost all parent measures was confirmed. But Hypotheses 1(a) and 1(c) were not supported for long term outcome of child and teacher measures.

Post-hoc analysis of reliable change was enlightening. Substantially more children in the CFT group than in the DTC group demonstrated reliable change for each outcome measure at $\mathrm{T} 2$. The numbers of children demonstrating reliable change eroded for CFT at T3. However, many more children showed levels of change just below the 2 Standard Error criterion. Furthermore, after CFT treatment, over $87 \%$ of children showed reliable change on at least one outcome measure and many showing reliable change on 3 or four measures. Two-thirds of children in the CFT group showed reliable change on at least one measure at follow-up (T3).

\section{Limitations of the Present Results}

Selection criteria for the study focused upon children with ASD who were very high-functioning (e.g., attending a regular classroom without an aide, having significant preexisting communicative and social skills such as the ability to shift topics in conversations and knowledge of rules of board and school yard games). This was done in order to maintain homogeneity in social level of the CFT classes, as children with ASD were integrated into groups composed from a general outpatient clinic sample given a manualized treatment with a relatively narrow focus. Our previous experience running over 90 groups using this manual was instrumental in developing these selection criteria. Thus the present findings are limited to a select subsample of high functioning children with ASD.

Limitations were evident in outcome reported by teachers, children, and parents. Parent reports may have been influenced by the parent being an active implementer of treatment. It would be helpful to validate parent observations through the use of independent observers coding the play dates, perhaps with time sampling techniques. Another approach would be to have an alternative control group targeting objectives other than friendships which would be hypothesized to produce beneficial effects in other domains of functioning. Parent reports of improvement in the CFT group but not the alternative treatment group would be stronger evidence of improvements generalizing to the home.

The findings for numbers of hosted play dates indicated twice as many play dates at post-test than at baseline, which appears to be clinically significant. However, CFT modules encourage inviting other children over, so that this was not surprising. Furthermore, there was significant regression towards baseline levels of more solitary behavior on play dates. Despite improving significantly in the number of hosted play dates, children in the CFT condition were not invited on significantly more play dates. CFT may be of benefit to more children with ASD if pretraining sessions were given to overcome their initial social anxiety or in how to distract themselves from repetitive thoughts. The treatment effects may be substantially augmented with training in understanding other children's point of view, either before or after the administration of CFT. It remains for future research to establish the benefits of these combinations.

Teacher data was not obtained for between 11.4 and $15.2 \%$ of children. Analysis revealed that teachers were less likely to report on children that parents rated as having more externalizing behaviors, so that teacher data must be viewed with some caution. Teachers did not report significant improvement in aggression or withdrawal at school for the CFT group as a whole. While the lack of significant findings for aggression could be ascribed to low baseline levels on this scale, baseline levels for withdrawal were quite high. Although the children in the CFT condition reported immediate improvement in loneliness and popularity, these effects did not persist through follow-up for the group as a whole.

\section{Conclusions}

Frankel et al. (2010) recently reported relationships between play date measures and observation of peer interaction on the school playground. They noted that hosted play dates showed substantial correlation with two important indices of peer acceptance: joint engagement and positive peer response to the initiations of the child with ASD. Thus it is possible that gains in hosted play dates noted in the present study may eventually result in gains on the school playground. In contrast, reciprocated play date invitations may be a product of more complex factors, for instance the attitude of other parents regarding the importance of play dates. Play date reciprocation is an indication of the development of closer friendship (Frankel 2010). Perhaps the development of closer friends reflected in reciprocal play dates takes substantially longer than the 3 month follow-up of this study. It was hoped that, once instructed on how to promote and supervise play dates for their children, parents would continue the critical elements of this program in the longer term. It is clear that the 12 one-hour sessions of the program were not enough to change the social behavior of many children with ASD. Further research must explore these issues.

La Greca (1993) has advocated promoting best friendships in addition to enhancing peer acceptance, and utilizing parents in a manner that easily lends itself to clinical 
practice. Outpatient group treatment can accomplish these goals. A key link for the development of best friends in children with ASD may be training of skills necessary to have successful one-on-one play dates. Outpatient sessions can be scheduled at times when parents are likely to be involved in treatment. Parents can be used to actively promote play dates.

The CFT intervention reported here was carried out in context of a regular outpatient clinical service. Many children in the study were referred for social skills training by community practitioners. A relatively low drop out rate was observed through the end of treatment (5 of 40 CFT children or $12.5 \%$ ), typical of that encountered by the authors over the past 12 years that the clinical service has been offered. It has been feasible to implement this intervention in a clinical setting. It is also cost effective, being delivered to groups of 10 children at a time and utilizing only three professionals.

Acknowledgment This research was supported by NIH Research Grant U54 MH68172 funded by the National Institute of Mental Health, NICHD, NIDCD and NINDS, Marian Sigman, STAART Center Program Principal Investigator and Fred Frankel, Project Principal Investigator. The contents of this publication are solely the responsibility of the authors and do not necessarily represent the official views of the NIH. The authors gratefully acknowledge the invaluable assistance of Pegeen Cronin, Ph.D. and staff of the UCLA Center for Autism Research and Treatment evaluation core.

Open Access This article is distributed under the terms of the Creative Commons Attribution Noncommercial License which permits any noncommercial use, distribution, and reproduction in any medium, provided the original author(s) and source are credited.

\section{References}

Asher, S. R., Hymel, S., \& Renshaw, P. D. (1984). Loneliness in children. Child Development, 55, 1456-1464.

Attwood, T. (2000). Strategies for improving the social integration of children with Asperger syndrome. Autism, 4, 85-100.

Badenes, L. V., Estevan, R. A. C., \& Bacete, J. G. (2000). Theory of mind and peer rejection at school. Social Development, 9, 271-283.

Bauminger, N. (2007). Brief report: Individual social-multimodal intervention for HFASD. Journal of Autism and Developmental Disorders, 37, 1593-1604.

Bauminger, N., \& Kasari, C. (2000). Loneliness and friendship in high-functioning children with autism. Child Development, 71, 447-456.

Bauminger, N., Schulman, C., \& Agam, G. (2003). Peer interaction and loneliness in high-functioning children with autism. Journal of Autism and Developmental Disorders, 33, 489-507.

Bauminger, N., Solomon, M., Aviezer, A., Heung, K., Brown, K., Brown, J., et al. (2008). Friendship in high-functioning children with autism spectrum disorder: Mixed and non-mixed dyads. Journal of Autism and Developmental Disorders, 38, 12111229.

Baxter, A. (1997). The power of friendship. Journal on Developmental Disabilities, 5(2), 112-117.
Bellini, S., Peters, J. K., Benner, L., \& Hopf, A. (2007). A metaanalysis of school-based social skills interventions for children with autism spectrum disorders. Remedial and Special Education, 28, 153-162.

Black, B., \& Hazen, N. L. (1990). Social status and patterns of communication in acquainted and unacquainted preschool children. Developmental Psychology, 26, 379-387.

Buhrmester, D. (1990). Intimacy of friendship, interpersonal competence, and adjustment during preadolescence and adolescence. Child Development, 61, 1101-1111.

Burack, J. A., Root, R., \& Zigler, E. (1997). Inclusive education for students with autism: Reviewing ideological, empirical, and community considerations. In D. J. Cohen \& F. Volkmar (Eds.), Handbook of autism and pervasive developmental disorders (pp. 796-807). New York: Wiley.

Capps, L., Sigman, M., \& Yirmiya, N. (1996). Self-competence and emotional understanding in high-functioning children with autism. Development and Psychopathology, 7, 137-149.

Chamberlain, B., Kasari, C., \& Rotheram-Fuller, E. (2007). Involvement or Isolation? The social networks of children with autism in regular classrooms. Journal of Autism and Developmental Disorders, 37, 230-242.

Cohen, J. (1988). Statistical power analysis for the behavioral sciences (2nd ed.). Hillsdale: N.J. Erlbaum.

Ehlers, S., Gillberg, C., \& Wing, L. (1999). A screening questionnaire for Asperger syndrome and other high-functioning autism spectrum disorders in school age children. Journal of Autism and Developmental Disorders, 29, 129-141.

Elliot, S. N., \& Gresham, F. M. (1993). Social skills intervention for children. Behavior Modification, 17, 287-313.

Frankel, F. (2005). Parent-assisted children's friendship training. In E. D. Hibbs \& P. S. Jensen (Eds.), Psychosocial treatments for child and adolescent disorders: Empirically based approaches (pp. 693-715). Washington, DC: American Psychological Association.

Frankel, F. (2010). Friends forever: How parents can help their kids make and keep good friends. San Francisco: Jossey-Bass Publishers.

Frankel, F., Gorospe, C., \& Chang, Y. (2010). Mothers reports of play dates and observation of school playground behavior of children having high functioning autism. Manuscript submitted for publication.

Frankel, F., \& Myatt, R. (2003). Children's friendship training. New York: Brunner-Routledge.

Frankel, F., \& Myatt, R. (2007). Parent-assisted friendship training for children with Autism spectrum disorders: Effects associated with psychotropic medication. Child Psychiatry and Human Development, 37, 337-346.

Frankel, F., \& Mintz, J. (in press). Maternal reports of play dates of clinic referred and community children. Journal of Child and Family Studies.

Frankel, F., Myatt, R., \& Cantwell, D. P. (1995). Training outpatient boys to conform with the social ecology of popular peers: Effects on parent and teacher ratings. Journal of Clinical and Child Psychology, 24, 300-310.

Frankel, F., Myatt, R., Cantwell, D. P., \& Feinberg, D. T. (1997a). Parent assisted children's social skills training: Effects on children with and without attention-deficit hyperactivity disorder. Journal of the Academy of Child and Adolescent Psychiatry, 36, 1056-1064.

Frankel, F., Myatt, R., Cantwell, D. P., \& Feinberg, D. T. (1997b). Use of child behavior checklist and DSM-III-R diagnosis in predicting outcome of children's social skills training. Journal of Behavioral Therapy and Experimental Psychiatry, 28, 149-161.

Frankel, F., Myatt, R., Cantwell, D. P., \& Feinberg, D. T. (1999). Do stimulants improve self-esteem in children with ADHD and peer 
problems? Journal of Child and Adolescent Psychopharmacology, 9, 185-194.

Gresham, F. M., \& Elliott, S. N. (1990). Social skills rating system: Manual. Circle Pines, MN: American Guidance Service.

Hauck, M., Fein, D., Waterhouse, L., \& Feinstein, C. (1995). Social initiations by autistic children to adults and other children. Journal of Autism and Developmental Disorders, 25, 579-595.

Hollingshead, A.B. (1975). Four factor index of social status. Unpublished manuscript. Available from P.O. Box 1965, Yale Station, New Haven, CT 06520, USA.

Hwang, B., \& Hughes, C. (2000). The effects of social interactive training on early social communicative skills of children with autism. Journal of Autism and Developmental Disorders, 30, 331-343.

Jacobson, N. S., \& Truax, P. (1991). Clinical significance: A statistical approach to defining meaningful change in psychotherapy research. Journal of Consulting and Clinical Psychology, 59, 12-19.

La Greca, A. M. (1981). Peer acceptance: The correspondence between children's sociometric scores and teachers' ratings of peer interactions. Journal of Abnormal Child Psychology, 9, 167-178.

La Greca, A. M. (1993). Social skills training with children: Where do we go from here? Journal of Clinical Child Psychology, 22, 288-298.

Laugeson, E. A., Frankel, F., Mogil, C., \& Dillon, A. R. (2009). Parent-assisted social skills training to improve friendships in teens with Autism spectrum disorders. Journal of Autism and Developmental Disorders, 39, 596-606.

Ledingham, J. E. (1981). Developmental patterns of aggressive and withdrawn behavior in childhood: A possible method for identifying preschizophrenics. Journal of Abnormal Child Psychology, 9, 1-22.

Ledingham, J. E., \& Younger, A. (1985). The influence of the evaluator on assessments of children's social skills. In B. H. Schneider, K. H. Rubin, \& J. E. Ledingham (Eds.), Children's peer relations: Issues in assessment and intervention (pp. 111121). New York: Springer-Verlag.

Ledingham, J. E., Younger, A., Schwartzman, A., \& Bergeron, G. (1982). Agreement among teacher, peer and self- ratings of children's aggression, withdrawal and likability. Journal of Abnormal Child Psychology, 10, 363-372.

Liu, J., Nyholt, D. R., Magnussen, P., Parano, E., Pavone, P., Geschwind, D., et al. (2001). A genomewide screen for autism susceptibility loci. American Journal of Human Genetics, 69, 327-340.

Lord, C., Risi, S., Lambrecht, L., Cook, E. H., Leventhal, B. L., DiLavore, P. C., et al. (2000). The Autism diagnostic observation schedule-generic: A standard measure of social and communication deficits associated with the spectrum of autism. Journal of Autism and Developmental Disorders, 30, 205-223.

Lord, C., Rutter, M., \& Le Couter, A. (1994). Autism diagnostic interview-revised: A revised version of a diagnostic interview for caregivers of individuals with possible pervasive developmental disorders. Journal of Autism and Developmental Disorders, 24, 659-685.

Macintosh, K., \& Dissanayake, C. (2006). Social skills and problem behaviors in school aged children with high-functioning autism and Asperger's disorder. Journal of Autism and Developmental Disorders, 36, 1065-1076.

Marriage, K. J., Gordon, V., \& Brand, L. (1995). A social skills group for boys with Asperger's syndrome. Australian and New Zealand Journal of Psychiatry, 29, 58-62.

McConnell, S. R. (2002). Interventions to facilitate social interaction for young children with autism: Review of available research and recommendations for educational intervention and future research. Journal of Autism and Developmental Disorders, 32, 351-372.

McGuire, K. D., \& Weisz, J. R. (1982). Social cognition and behavior correlates of preadolescent chumship. Child Development, 53, $1478-1484$

Miller, P. M., \& Ingham, J. G. (1976). Friends, confidants, and symptoms. Social Psychiatry, 11, 51-58.

Moncher, F. J., \& Prinz, R. J. (1991). Treatment fidelity in outcome studies. Clinical Psychology Review, 11, 247-266.

Nelson, J., \& Aboud, F. E. (1985). The resolution of social conflict between friends. Child Development, 56, 1009-1017.

O’Connor, M. J., Frankel, F., Paley, B., Schonfeld, A. M., Carpenter, E., Laugeson, E., et al. (2006). A controlled social skills training for children with fetal alcohol spectrum disorders. Journal of Consulting and Clinical Psychology, 74(4), 639-648.

Ozonoff, S., \& Miller, J. N. (1995). Teaching theory of mind: A new approach to social skills training for individuals with autism. Journal of Autism and Developmental Disorders, 25, 415-433.

Parke, R. D., Burks, V. M., Carson, J. L., Neville, B., \& Boyum, L. A. (1994). Family peer relationships: A tripartite model. In R. D. Parke \& S. G. Kellam (Eds.), Exploring family relationships with other social contexts (pp. 115-145). New York: Routledge.

Pekarik, E., Prinz, R., Liebert, D., Weintraub, S., \& Neil, J. (1976). The pupil evaluation inventory: A sociometric techniques for assessing children's social behavior. Journal of Abnormal Child Psychology, 4, 83-97.

Piers, E. V. (1984). Piers-Harris children's self-concept scale-revised manual. Los Angeles: Western Psychological Services.

Pope, A. W., Bierman, K. L., \& Mumma, G. H. (1991). Aggression, hyperactivity, and inattention-immaturity: Behavior dimensions associated with peer rejection in elementary school boys. Developmental Psychology, 27, 663-671.

Prior, M., Leekam, S., Ong, B., Eisenmajer, R., Wing, L., Gould, J., et al. (1998). Are there subgroups with in autism spectrum? A cluster analysis of a group of children with autism spectrum disorder. Journal of Child Psychology and Psychiatry, 39, 893902.

Rose, A. J., \& Asher, S. R. (1999). Children's goals and strategies in response to conflicts within a friendship. Developmental Psychology, 35, 69-79.

Shaked, M., \& Yirmiya, N. (2003). Understanding social difficulties. In M. Prior (Ed.), Learning and behavior problems in Asperger syndrome (pp. 104-205). New York: Guilford.

Sigman, M., \& Ruskin, E. (1999). Continuity and change in the social competence of children with autism, down syndrome, and developmental delays. Monograph of the Society for Research in Child Development, 64, 114.

Sim, L., Whiteside, S. P., Dittner, C. A., \& Mellon, M. (2006). Effectiveness of a social skills training program with school age children: Transition to the clinical setting. Journal of Child and Family Studies, 15, 409-418.

Sparrow, S. S., Balla, D. A., \& Cicchetti, D. V. (1984). Vineland adaptive behavior scales. Circle Pines, MN: American Guidance Service, Inc.

Tremblay, R. E., LeBlanc, M., \& Schwartzman, A. E. (1988). The predictive power of first-grade peer and teacher ratings of behavior: Sex differences in antisocial behavior and personality at adolescence. Journal of Abnormal Child Psychology, 16, 571583.

Wechsler, D. (1991). WISC-III manual. New York: The Psychological Corporation.

Wolfberg, P. J., \& Schuler, A. L. (1993). Integrated play groups: A model for promoting the social and cognitive dimensions of play in children with autism. Journal of Autism and Developmental Disorders, 23(3), 467-489. 